\title{
An Educational Telenovela (Soap Opera) Approach to Promote Breastfeeding Among U.S. Latinas
}

\author{
Belinda Prado ${ }^{1}$, Shari McMahan ${ }^{1}$, Michele Mouttapa ${ }^{1}$, Irene Salazar ${ }^{2}$, \\ Gail Love ${ }^{1}$ and Sherry Norwood ${ }^{3}$ \\ ${ }^{1}$ California State University, Fullerton \\ ${ }^{2}$ Planned Parenthood \\ ${ }^{3}$ Planned Parenthood Women, Infants, and Children
}

\begin{abstract}
Breastfeeding provides infants with more nutritional value, higher immune resistance, and lower rates of obesity later in life relative to infant formula. In order to promote breastfeeding a "telenovela" (soap opera) approach was used to educate pregnant recipients of the Women Infants and Children (WIC) program about the benefits of breastfeeding. Participants were assigned to either a control group, who received standard education from WIC, or the intervention group, who received standard WIC education plus viewing the telenovela. Our analyses did not demonstrate any significant differences between the control group and intervention group on changes in attitudes towards breastfeeding immediately before and after the intervention. However, important lessons were learned about conducting community research; using the telenovela engaged participants in conversations about breastfeeding with their health educator and can be used for additional support in creating and delivering effective breastfeeding messages.
\end{abstract}

(C) 2012 Californian Journal of Health Promotion. All rights reserved.

Keywords: breastfeeding, entertainment education, latinas, Santa Ana

\section{Introduction}

The promotion of breastfeeding is of utmost importance because of its role in many healthrelated outcomes. Infants who are breastfed at least six months experience lower incidence rates of diarrhea, ear infections, pneumonia, sudden infant death syndrome (SIDS), asthma, and obesity (Wolf, 2000). A protective factor against childhood obesity is increasing the duration and exclusivity of breastfeeding. Infants who are breastfed for less than two months are four times more likely to become obese in comparison to children who were breastfed for an entire year (Wolf, 2000). In addition, children who are formula fed within the first week of birth are more likely to become obese as adults (Stettler, Stallings, Troxel, Zhao, \& Schinnar et. al., 2005). It is well documented that childhood obesity may lead to type 2 diabetes, problems sleeping, high blood pressure and cardiovascular disease (Gardner, Gardner \& Sowers, 2008). Once a child becomes obese, he/she is more likely to stay obese as an adult and have one or more of the chronic diseases mentioned above (Stettler, Stallings, Troxel, Zhao, \& Schinnar, et al., 2005). Thus, one of the best preventive measures for childhood obesity is breastfeeding (Swartz, 2009). Not only is breastfeeding beneficial for the infant; it also provides mothers with numerous health benefits, including loss of pregnancy weight and reduced risk of ovarian and breast cancer (The American Academy of Pediatrics, 1997).

\section{Breastfeeding among Latinas}

The Latino/Hispanic population is steadily growing in the United States and was projected to increase by $43 \%$, from 35.5 million in 2000 to 50.5 million in 2010 (U.S. Census Bureau, 
2011). The promotion of breastfeeding is particularly important for Latinas, as the U.S. Latino population suffers disproportionately from obesity and its related complications such as diabetes (CDC, 2010). Of particular concern is the low rate of breastfeeding among minority participants such as U.S. born Latinas (Heck, Braveman, Cubbin, Chávez, \& Kiely, 2006).

The majority of U.S. Latinas recognize that breastfeeding is important to the health of their baby. However, there are many obstacles that prevent Latinas from breastfeeding. Breastfeeding challenges include: embarrassment, pain, inconvenience, lack of breastfeeding support, and not being able to consume alcohol or smoke cigarettes (Gill, Reifsnider, Mann, Villarreal, \& Tinkle, 2004; Wood, Sasonoff, \& Beal, 1998). These barriers need to be addressed in a culturally sensitive manner that focuses on how women can overcome them.

\section{The Telenovela Approach}

While healthcare professionals generally encourage breastfeeding, there is a need for interventions that engage minority women in a meaningful way relative to traditional approaches, for example, the provision of pamphlets at OB-GYN visits. A telenovela (a soap opera-themed entertainment educational DVD) was developed with the intentions to target minority Latina women. A telenovela is a televised soap opera in Latin America, a type of melodramatic serialized fiction produced and aired in Latin American countries (Pan America Health Organization, 2003). Telenovelas have been previously used to convey messages and instigate change for a variety of public health issues including cancer, drug abuse, abandoned street children, gender equality and sexual responsibility (Pan America Health Organization, 2003). The telenovela approach is an ideal method of health education because women with lower literacy levels can follow the storyline and receive the health education lessons. Furthermore, the telenovela was in Spanish; hence women who were less fluent in English could also receive the message.
We implemented a telenovela intervention with pregnant, low-income Latina women utilizing Women, Infant and Children (WIC) services in a southern California city. The story, "Un Regalo Para El Bebe" ("A Gift for your Baby") was the name of the telenovela. The main character is a pregnant female that is having a baby shower. The soap opera begins with the main character's mother-in-law disapproving of her choice to breastfeed. However, her mother and friends interject and explain to the mother-in-law about the benefits of breastfeeding her child. They discuss the benefits of breastfeeding for both the newborn and the mother. The benefits discussed include having a decreased risk of childhood obesity, more postpartum weight loss for the mother, and decreased risk of breast cancer and diabetes. At the end of the baby shower the pregnant mother confirms that she is going to do what is best for her baby by breastfeeding. The length of the telenovela is 7.5 minutes.

We examined changes in attitudes about breastfeeding before and after watching the telenovela. We predicted that those mothers who received the telenovela intervention along with the standard counseling provided by WIC would have a more positive increase in attitudes towards breastfeeding compared to those mothers who only received the standard counseling.

\section{Methods}

\section{Study Design}

The study was a quasi-experimental design utilizing a convenience sample of participants receiving federal subsidies through the Women Infants Children (WIC) program. WIC provides supplemental foods, health care referrals, and nutrition education for low-income women who are either pregnant or postpartum, regardless of whether or not they breastfeed. The children of these women are age five or younger (Food and Drug Administration, 2005).

\section{Participants}

A total of 145 WIC participants participated in the study, with 69 Latinas in the intervention 
group and 76 Latinas in the control group. Participants were recruited from February 2009 to March 2010. The researchers alternated group assignment every month during the data collection phase; this was done to obtain roughly equivalent numbers of Latinas in each group. Furthermore, the monthly alternating group assignment strategy was an attempt to reduce the possibility that the treatment and control group women were exposed to differing outside influences that might have occurred over the course of several months (e.g., a surge in media advertising). Inclusion criteria included: women 18 years or older, Latina, in the last trimester of their pregnancy, Spanish speaking, and WIC program recipients who were in the waiting room when the study was implemented.

\section{Data Collection Procedures}

This study was approved by California State University, Fullerton's Institutional Review Board. Oral consent was obtained from each participant prior to her participation in the study. Data were collected via a collaborative partnership with the WIC program of Santa Ana, California. The telenovela was disseminated through three trained and hired Spanishspeaking recruiters. The recruiters were present at the WIC center five days per week. The recruiters approached potential participants, described the study, and determined whether they were eligible. Interested and eligible Latinas were then taken to a conference room, where they completed a baseline questionnaire. Participants assigned to the intervention group then viewed the telenovela, followed by their scheduled half-hour counseling session with a WIC health educator to discuss their pregnancy and infant feeding options. The Latinas then returned to the conference room to complete the post-baseline questionnaire. The procedures were consistent for the control group participants, except that they did not watch the telenovela. Latinas completed each questionnaire in approximately 20-25 minutes.

\section{Measures}

Survey questions included previous breastfeeding experience and attitudes toward breastfeeding. These measures were created based upon focus group responses from a previous study that investigated the factors contributing to low breastfeeding rates among Latinas. The questions were designed using a

Likert-like scale, ranging from $1=$ strongly disagree, to $5=$ strongly agree. Demographic variables included age, education level, marital status, birth country, English fluency and language most comfortable speaking.

\section{Table 1}

Demographic characteristics among WIC participants, 2009-2010

\begin{tabular}{|c|c|c|c|}
\hline & $\begin{array}{l}\text { Control } \\
\text { Group } \\
(\mathrm{n}=76)\end{array}$ & $\begin{array}{l}\text { Intervention } \\
\text { Group } \\
(\mathrm{n}=69)\end{array}$ & $\underline{\mathrm{p}}$ \\
\hline Age group (years) & & & .158 \\
\hline $18-25$ & $55.2 \%$ & $45.5 \%$ & \\
\hline $26-35$ & $28.4 \%$ & $45.5 \%$ & \\
\hline $36-45$ & $14.9 \%$ & $9.1 \%$ & \\
\hline 46 or older & $1.5 \%$ & $0.0 \%$ & \\
\hline Education Level & & & .777 \\
\hline Less than 12 years & $87.5 \%$ & $89.4 \%$ & \\
\hline 12 years or more & $12.5 \%$ & $10.6 \%$ & \\
\hline Birth Country* & & & $.021 *$ \\
\hline United States & $27.1 \%$ & $10.3 \%$ & \\
\hline Mexico & $71.4 \%$ & $83.8 \%$ & \\
\hline Other & $1.4 \%$ & $5.9 \%$ & \\
\hline Marital Status* & & & $.019 *$ \\
\hline Legally Married & $44.9 \%$ & $56.7 \%$ & \\
\hline Divorced/Separated & $10.1 \%$ & $1.5 \%$ & \\
\hline $\begin{array}{lr}\text { In a long } & \text { term } \\
\text { relationship } & \text { (never } \\
\text { married) } & \end{array}$ & $23.2 \%$ & $32.8 \%$ & \\
\hline Single (never married) & $21.7 \%$ & $9.0 \%$ & \\
\hline Widowed & $0.0 \%$ & $0.0 \%$ & \\
\hline English Fluency & & & .840 \\
\hline Fluent & $24.3 \%$ & $16.2 \%$ & \\
\hline Well & $12.9 \%$ & $14.7 \%$ & \\
\hline Fair & $11.4 \%$ & $13.2 \%$ & \\
\hline Poor & $24.3 \%$ & $26.5 \%$ & \\
\hline Not at all & $27.1 \%$ & $29.4 \%$ & \\
\hline $\begin{array}{l}\text { Language most } \\
\text { comfortable speaking }\end{array}$ & & & .848 \\
\hline Only Spanish & $47.1 \%$ & $52.9 \%$ & \\
\hline Mostly Spanish & $20.0 \%$ & $17.6 \%$ & \\
\hline $\begin{array}{l}\text { Both English and } \\
\text { Spanish }\end{array}$ & $22.9 \%$ & $22.1 \%$ & \\
\hline Mostly English & $8.6 \%$ & $7.4 \%$ & \\
\hline Only English & $1.4 \%$ & $0.0 \%$ & \\
\hline
\end{tabular}


Prado, B., McMahan, S., Mouttapa, M., Salazar, I., Love, G., \& Norwood, S. / Californian Journal of Health Promotion 2012, Volume 10, Special Issue: Obesity Prevention and Intervention, 57-63

Table 2

Background Characteristics about Previous Breastfeeding Experience, 2009-2010

\begin{tabular}{|c|c|c|c|}
\hline & $\begin{array}{l}\text { Control } \\
\text { Group } \\
(n=76)\end{array}$ & $\begin{array}{c}\text { Intervention } \\
\text { Group } \\
(n=69)\end{array}$ & $\mathrm{p}$ \\
\hline & yes $\%$ & yes $\%$ & \\
\hline Not the first pregnancy* & $30.8 \%$ & $38.5 \%$ & $.009 * *$ \\
\hline Breastfeed last baby* & $29.8 \%$ & $37.1 \%$ & $.026 *$ \\
\hline Main reason previous baby was breastfed? & & & .385 \\
\hline It was easier than bottle feeding & $2.4 \%$ & $6.1 \%$ & \\
\hline It was cheaper than bottle feeding & $0.0 \%$ & $0.0 \%$ & \\
\hline It was good for me & $0.0 \%$ & $1.2 \%$ & \\
\hline It was good for my baby & $46.3 \%$ & $53.7 \%$ & \\
\hline Why did you stop breastfeeding your last baby? & & & .263 \\
\hline It was painful & $2.9 \%$ & $10.1 \%$ & \\
\hline It was better to bottle feed & $2.9 \%$ & $4.3 \%$ & \\
\hline It was hard to do when I went back to work & $13 \%$ & $7.2 \%$ & \\
\hline I couldn't make the breast pump work & $4.3 \%$ & $4.3 \%$ & \\
\hline They no longer needed to be breastfed & $17.4 \%$ & $31.9 \%$ & \\
\hline
\end{tabular}

$* p<.05$. **p $<.01$.

Table 3

Attitudes toward Breastfeeding, 2009-2010

$\begin{array}{ccc}\text { Control } & \text { Intervention } & \\ \text { Group } & \text { Group } & \beta \\ M(\text { SD) } & \mathrm{M}(\mathrm{SD}) & (\mathrm{p})\end{array}$

\begin{tabular}{|c|c|c|c|c|c|}
\hline & Baseline & $\begin{array}{c}\text { Post- } \\
\text { Baseline }\end{array}$ & Baseline & $\begin{array}{c}\text { Post- } \\
\text { Baseline }\end{array}$ & \\
\hline I am embarrassed to breastfeed. & $2.23(1.57)$ & $1.97(1.41)$ & $1.89(1.38)$ & $1.62(1.23)$ & $-.151(.11)$ \\
\hline $\begin{array}{l}\text { Breastfeeding can help protect you from } \\
\text { breast cancer. }\end{array}$ & $4.18(1.14)$ & $4.14(1.20)$ & $4.41(1.04)$ & $4.57(1.02)$ & $.060(.54)$ \\
\hline Breastfeeding my baby is healthy for me. & $4.59(1.10)$ & $4.66(1.02)$ & $4.37(1.25)$ & $4.53(1.21)$ & $-.148(.13)$ \\
\hline $\begin{array}{l}\text { Breastfeeding my baby is healthy for my } \\
\text { baby. }\end{array}$ & $4.62(1.15)$ & $4.73(0.98)$ & $4.61(1.07)$ & $4.67(1.02)$ & $-.048(.62)$ \\
\hline $\begin{array}{l}\text { If I have another baby I will probably } \\
\text { breastfeed it. }\end{array}$ & $4.35(1.41)$ & $4.49(1.22)$ & $4.40(1.22)$ & $4.58(1.05)$ & $.036(.71)$ \\
\hline $\begin{array}{l}\text { I don't see how breastfeeding has anything to } \\
\text { do with breast cancer. }\end{array}$ & $2.71(1.51)$ & $2.76(1.51)$ & $2.41(1.40)$ & $2.08(1.49)$ & $-.095(.35)$ \\
\hline $\begin{array}{l}\text { I have to go back to work so I can't } \\
\text { breastfeed. }\end{array}$ & $1.93(1.37)$ & $1.85(1.25)$ & $2.30(1.32)$ & $2.02(1.40)$ & $.135(.18)$ \\
\hline $\begin{array}{l}\text { Breastfeeding can help babies from getting } \\
\text { too fat later. }\end{array}$ & $3.44(1.44)$ & $3.57(1.44)$ & $3.35(1.56)$ & $3.80(1.55)$ & $-.031(.76)$ \\
\hline
\end{tabular}

Results

\section{Characteristics by Intervention and Control Group}

Table 1 presents demographic characteristics by intervention and control group. The intervention group had a higher proportion of participants who were born in Mexico $(\mathrm{p}<.05)$ and were 
married $(\mathrm{p}<.05)$. Birthplace and marital status were not associated with breastfeeding attitudes. Table 2 presents breastfeeding-related characteristics by intervention and control group. Significantly more women in the intervention group had previous pregnancies $(\mathrm{p}$ $<.01)$ and previous breastfeeding experience $(\mathrm{p}<$ $.05)$.

\section{Intervention Effects on Attitudes toward Breastfeeding}

Multiple linear regression tests were performed to assess intervention versus control group differences on each attitudinal variable at postbaseline. These analyses controlled for variables that were significantly associated with the posttest attitudinal scores in preliminary analyses, namely baseline attitudinal scores, pregnancy history, and previous breastfeeding experience. Out of the 8 variables analyzed there were no significant differences between the groups on attitudes post-baseline. See Table 3.

\section{Discussion}

The control and intervention groups did not differ from each other on attitudinal change towards breastfeeding from baseline to postbaseline, after taking into consideration differences between the control and intervention groups on demographic and breastfeeding-related characteristics. However, it is important to note that there was a trend for attitudes to change in the positive direction. It may be that messages created in the United States are most effective when provided in a systematic manner (e.g., standardized WIC visits) to increase positive attitudes towards breastfeeding. The telenovela intervention may have significantly affected constructs (e.g., social support) that we did not measure that also predict breastfeeding. For example, studies have shown that Latina women feel more support regarding breastfeeding in their home country than in America (Sussner, Lindsay, Greaney, \& Peterson, 2008). It is possible that a telenovela such as "Un Regalo Para El Bebe" might act as a first step in addressing more culturally sensitive issues associated with friends and family members supporting breastfeeding. Although not recorded as a survey item, health educators were asked to keep track of how many questions were asked by the WIC participants. It was observed that more questions were asked by the intervention group than the control group about breastfeeding when communicating with the WIC health educator.

The findings of this study may or may not generalize to all pregnant Latinas in the U.S., as our sample was obtained from one WIC location. Ideally, our sample would have only included women who were pregnant for the first time. Secondly, conducting postpartum followup assessments in the field posed challenges. Many women scheduled follow-up appointments but missed them due to transportation or other related issues. Hence, we were not able to obtain a representative sample of participants to determine whether there were any intervention effects on continued breastfeeding at specific developmental stages (e.g., 6 months and 12 months postpartum). Furthermore, it is possible that attitude change may not occur immediately after viewing the telenovela. Therefore, a follow-up assessment is needed to more conclusively evaluate the effectiveness of the telenovela on increasing attitudes towards breastfeeding and breastfeeding behavior.

\section{Implications of the Study}

A telenovela intervention was created as a means to convey information to Latinas using a type of medium (e.g. a telenovela) that is popular in the Latino culture. There was no significant difference between the intervention and control groups on changes in attitudes regarding breastfeeding. However, it was observed that women who watched the video were more likely to engage in conversations with the health educator about breastfeeding. This may be the first step of many messages that can demonstrate support for breastfeeding in the United States. 
Prado, B., McMahan, S., Mouttapa, M., Salazar, I., Love, G., \& Norwood, S. / Californian Journal of Health Promotion 2012,

Volume 10, Special Issue: Obesity Prevention and Intervention, 57-63

\section{References}

American Academy of Pediatrics Work Group on Breastfeeding. (1997). Breastfeeding and the use of human milk. Pediatrics, 100, 1035-1039.

Center for Disease Control and Prevention. (2010). Obesity prevalence among lowincome preschool-aged children 1998-2008. Retrieved April 1, 2010, from http://www.cdc.gov/obesity/childhood/lowincome.html

Food and Drug Administration. (2005). Women, Infants and Children. Retrieved March 12, 2010, from http://www.fns.usda.gov/wic/

Gardner, M., Gardner, D., \& Sowers, J. (2008). The cardiometabolic syndrome in the adolescent, Pediatric Endocrinology Reviews, 5, 964-968.

Gill, S. L., Reifsnider E., Mann, A. R., Villarreal, P., \& Tinkle, M. B. (2004). Assessing infant breastfeeding beliefs among low-income Mexican Americans. The Journal of Perinatal Education, 13, 39-50.

Heck, K.E., Braveman, P., Cubbin, C., Chávez, G. F., \& Kiely, J.L. (2006). Socioeconomic Status and Breastfeeding Initiation Among California Mothers. Public Health Reports,121(1), 51-59.

Pan American Health Organization. (2003). Telenovelas an Ideal Medium for Health Messages. Retrieved May 5, 2010, from http://www.paho.org/english/dd/pin/pr030904.htm.

Stettler, N., Stallings, V., Troxel, A., Zhao, J., Schinnar, R., Nelson, S., . . Ziegler, E. (2005). Weight gain in the first week of life and overweight in adulthood: A cohort study of European American subjects fed infant formula. Journal of the American Heart $\quad$ Association, 111, 18971903.

Sussner, K.M., Lindsay, A.C., Greaney, M.L., \& Peterson, K.E. (2008). The influence of immigrant status and acculturation on the development of overweight in Latino families: A qualitative study. Journal of Immigrant Minority Health, 10(6), 497-505.

Swartz, M. (2009). Focus on overweight and obesity prevention and management. Journal of Pediatric Health Care, 23, 9-20.

U.S. Department of Census 2010. (2011). The Hispanic Population: 2010. Retrieved May 5, 2012, from http://www.census.gov/prod/cen2010/briefs/c2010br-04.pdf

Wolf, J. H. (2000). Low breastfeeding rates. American Journal of Public Health Association, 93(12), 2000-2010.

Wood, S.P., Sasonoff, K.M., \& Beal, J.A. (1998). What's happening breastfeeding attitudes and practices of Latino women: Descriptive study. Journal of the American Academy of Nurse Practitioner, 10, 253-260.

\section{Author Information}

*Belinda Prado MPH

Department of Health Science

Telephone: (714) 329-6832

Email: bprado77@csu.fullerton.edu

Shari McMahan $\mathrm{PhD}$

California State University, Fullerton

College of Health and Human Development

Michele Mouttapa PhD

California State University, Fullerton

Department of Health Science 
Prado, B., McMahan, S., Mouttapa, M., Salazar, I., Love, G., \& Norwood, S. / Californian Journal of Health Promotion 2012, Volume 10, Special Issue: Obesity Prevention and Intervention, 57-63

Irene Salazar NSLM

Planned Parenthood of Orange \& San Bernardino Counties

Gail Love PhD

California State University, Fullerton

Department of Communications

Sherry Norwood RD

Planned Parenthood

Women, Infants, and Children (WIC), Orange County

* corresponding author 